SECTION 7. Mechanics and machine construction.

\author{
Grinchenko Vitaliy Anatolyevich \\ Candidate of Engineering Sciences, Senior professor \\ Stavropol state agrarian University
}

\title{
JUSTIFICATION OF THE BASIC DESIGN OF A LINEAR ELECTRIC MOTOR
}

The paper proposes a method of justifying the basic design of a linear electric motor. This method allows you to select the source data for the design and shows the principle of the development of new designs of linear electric motors.

Keywords: linear electric motor, actuator, traction characteristics, magnetic, coils of magnetizing.

\section{ОБОСНОВАНИЕ БАЗОВОЙ КОНСТРУКЦИИ ЛИНЕЙНОГО ЭЛЕКТРОДВИГАТЕЛЯ}

В статье описывается метод обоснования базовой конструкиии линейного электродвигателя. Этот метод позволяет выбрать исходные данные для проектирования и показывает принции разработки новых конструкций линейных электродвигателей.

Ключевые слова: линейный электродвигатель, исполнительный механизм, тяговая характеристика, магнитопровод, намагничивающие катушки.

В машиностроении, агротехнике, медицине, гидро- и пневмотехнике существует огромное количество исполнительных механизмов, совершающих возвратнопоступательные перемещения заданной амплитуды. В основном такие устройства миниатюрны и требуют создания плавных перемещений. Наиболее перспективным способом управления их перемещением является электрический привод. К такому типу привода относятся линейные электродвигатели, подвижная часть которых непосредственно связана с перемещаемыми массами [1, с. 37]. Приводы с линейными электродвигателями встраиваются в оборудование и разрабатываются специально для решения конкретных технологических задач. Их использование по сравнению с серийными электродвигателями создает дополнительные трудности, связанные с необходимостью индивидуальной разработки конструкции для каждого устройства в отдельности. Но при таком подходе повышается эффективность технологического оборудования в целом, а также появляется возможность оптимально использовать ресурсы электрического привода [2, с. 206].

Основным условием в описанном случае является плавность перемещения, которая возможна при гиперболической тяговой характеристике. Ее создают линейные электродвигатели с прямоугольной формой полюсов якоря и магнитопровода [3, с. 68]. Эту конструкцию магнитной системы выбираем за базовую. Общепринятой классификации конструкций магнитных систем линейных электродвигателей не существует, поэтому базовую конструкцию охарактеризуем терминами, используемыми авторитетными авторами. По предложенной классификации в [4, с. 49] гиперболический вид тяговой характеристики обеспечивает конструкция из двух симметричных цилиндрических магнитопроводов с плоским прямоходовым якорем. Используя терминологию из [5, с. 15], базовую конструкцию можно охарактеризовать как состоящую из двух симметричных нейтральных магнитных систем соленоидного типа. 
Согласно [6, с. 63] базовую конструкцию охарактеризуем как с внешним тарельчатым якорем.

Базовая конструкция любого линейного электродвигателя имеет следующие особенности [4, с. 58]:

- материалы для ее изготовления обычные для электрических машин;

- размеры магнитной системы электродвигателя рассчитываются таким образом, что между ее эквивалентной индуктивностью и величиной эквивалентного воздушного зазора существует прямо пропорциональная зависимость;

- ток трогания якоря при номинальной механической нагрузке составляет $40 \%$ от номинального;

- подшипниковые элементы выполняются из немагнитных материалов для исключения прилипания якоря.

Кроме того, линейные электродвигатели получают все большее распространение благодаря следующему [3, с. 18]:

- накоплен определенный опыт в разработке и производстве линейных электродвигателей для конкретных механизмов;

- промышленностью выпускаются магнитомягкие материалы, имеющие большую индукцию насыщения и обладающие сравнительно большим удельным электрическим сопротивлением, что позволяет сократить потери на перемагничивание и токи Фуко;

- современный уровень технологий позволяет осуществлять массовое производство данного оборудования;

- высокий уровень развития электронных компонентов, позволяющих разрабатывать системы управления любыми технологическими процессами.

Учитывая опыт разработки описанных конструкций магнитных систем и требования, предъявляемые к ним, предлагается базовая конструкция линейного электродвигателя (рис. 1). Эта конструкция была разработана с помощью описанного выше метода [7, с. 5]. Линейный электродвигатель состоит из двух цилиндрических магнитопроводов 5 с намагничивающими катушками 4 и 7. В осевое отверстие магнитопроводов 5 вставлен шток 3, на котором закреплен якорь 6. Якорь 6 состоит из двух магнитных дисков 1 и немагнитной прослойки 2. Линейный электродвигатель работает следующим образом. При включении катушки 7, протекающий в ней ток индуцирует магнитное поле, силовые линии которого замыкаются через магнитопровод 5 и магнитную вставку 1. При этом возникает сила, перемещающая якорь 6 вверх. Усилие на якоре 6 передается через шток 3 исполнительному механизму. Увеличение тока на катушке 7, приводит к увеличению скорости перемещения якоря 6. Ток, поступая на катушку 4, создает магнитное поле, под действием которого якорь 6 стремится опуститься вниз. Увеличение тока на катушке 4 нарушает равновесие между силами и якорь 6 опускается вниз. Таким образом, подавая на катушки 4 и 7 токи определенной величины можно изменять положение якоря 6. Задавая динамику перемещения якоря, появляется возможность управлять перемещением исполнительного механизма.

Питание катушек 4 и 7 осуществляется с использованием широтно-импульсной модуляции, среднее значение тока в них определяется скважностью широтноимпульсной модуляции. Для того, чтобы добиться плавности и предсказуемости перемещения якоря электродвигателя под действием магнитодвижущей силы, в схеме блока управления организовано два контура отрицательной обратной связи. Косвенным параметром текущего положения якоря является действующее значение тока, протекающего в катушках линейного электродвигателя. 


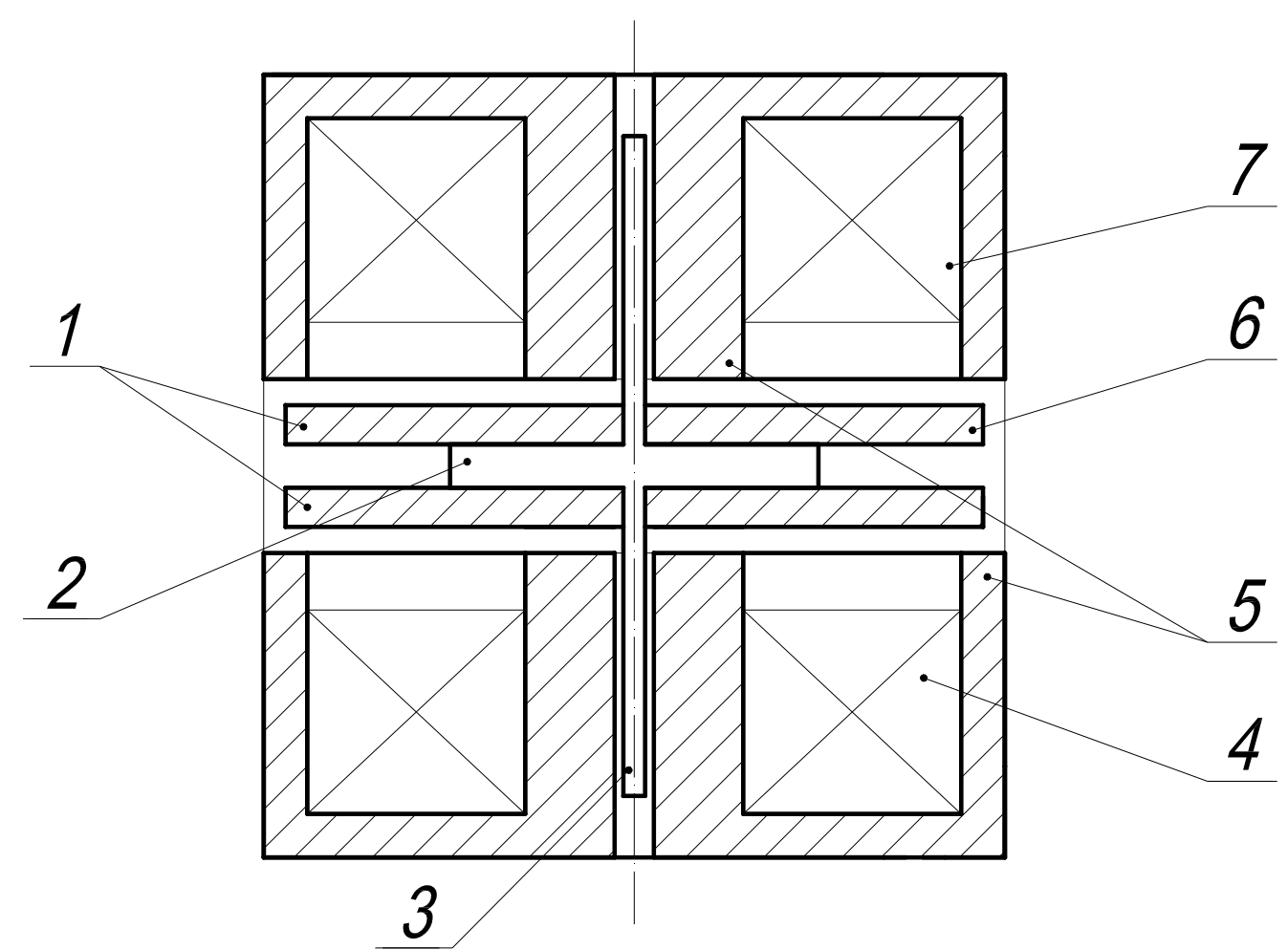

Рисунок 1 - Линейный электродвигатель для привода клапанного механизма пульсатора: 1 - магнитопроводящие диски; 2 - немагнитная прослойка якоря; 3 шток; 4, 7 - намагничивающие катушки; 5 - магнитопроводы; 6 - якорь

Описанный метод позволяет обосновать базовую конструкцию линейного электродвигателя при разработке исполнительных механизмов, совершающих возвратно-поступательные перемещения заданной амплитуды. При этом конструкторам необходимо учитывать условие создания электродвигателем максимального усилия при минимальных затратах стали для изготовления деталей магнитной системы и меди для намагничивающих катушек.

\section{Список литературы:}

1. Свечарник Д.В. Электрические машины непосредственного привода. М.: Энергоатомиздат, 1988. 208 с.

2. Глухов В.П. Моделирование статических электромагнитных устройств. - Рига: Знание, 1990. 304 с.

3. Овчинников С.В. Усовершенствование методов проектирования электромагнитных исполнительных механизмов и их разработка для электронных систем управления транспортным дизелем: дис.... канд. техн. наук: 05.13.05. Ярославль, 2003. $170 \mathrm{c.}$ $154 \mathrm{c}$.

4. Гурницкий В.Н. Линейный управляющий двигатель. Ставрополь: ССХИ, 1991.

5. Филипченко И.П., Рыбкин Г.Я. Электромагнитные реле. М.: Советское радио, 1968. $72 \mathrm{c.}$

6. Сливинская А.Г. Электромагниты и постоянные магниты. М.: Энергия, 1972. $148 \mathrm{c}$.

7. Патент на изобретение № 2370874 RU, МПК8 Н 02 K 33/12. Линейный двигатель / Г.В. Никитенко, В.А. Гринченко; заявитель и патентообладатель СтГАУ. № 2008112342/09; заявл. 31.03.08; опубл. 20.10.09. 